\title{
Antecedent flow conditions and nitrate concentrations in the Mississippi River basin
}

\author{
J. C. Murphy ${ }^{1}$, R. M. Hirsch ${ }^{2}$, and L. A. Sprague ${ }^{3}$ \\ ${ }^{1}$ Tennessee Water Science Center, US Geological Survey, Nashville, USA \\ ${ }^{2}$ National Research Program, US Geological Survey, Reston, USA \\ ${ }^{3}$ National Water-Quality Assessment Program, US Geological Survey, Boise, USA
}

Correspondence to: J. C. Murphy (jmurphy@usgs.gov)

Received: 30 August 2013 - Published in Hydrol. Earth Syst. Sci. Discuss.: 10 September 2013

Revised: 29 January 2014 - Accepted: 3 February 2014 - Published: 10 March 2014

\begin{abstract}
The relationship between antecedent flow conditions and nitrate concentrations was explored at eight sites in the 2.9 million square kilometers $\left(\mathrm{km}^{2}\right)$ Mississippi River basin, USA. Antecedent flow conditions were quantified as the ratio between the mean daily flow of the previous year and the mean daily flow from the period of record (Qratio), and the Qratio was statistically related to nitrate anomalies (the unexplained variability in nitrate concentration after filtering out season, long-term trend, and contemporaneous flow effects) at each site. Nitrate anomaly and Qratio were negatively related at three of the four major tributary sites and upstream in the Mississippi River, indicating that when mean daily streamflow during the previous year was lower than average, nitrate concentrations were higher than expected. The strength of these relationships increased when data were subdivided by contemporaneous flow conditions. Five of the eight sites had significant negative relationships $(p \leq 0.05)$ at high or moderately high contemporaneous flows, suggesting nitrate that accumulates in these basins during a drought is flushed during subsequent high flows. At half of the sites, when mean daily flow during the previous year was 50 percent lower than average, nitrate concentration can be from 9 to 27 percent higher than nitrate concentrations that follow a year with average mean daily flow. Conversely, nitrate concentration can be from 8 to 21 percent lower than expected when flow during the previous year was 50 percent higher than average. Previously documented for small, relatively homogenous basins, our results suggest that relationships between antecedent flows and nitrate concentrations are also observable at a regional scale. Relationships were not observed (using all contemporaneous flow data to-
\end{abstract}

gether) for basins larger than 1 million $\mathrm{km}^{2}$, suggesting that above this limit the overall size and diversity within these basins may necessitate the use of more complicated statistical approaches or that there may be no discernible basin-wide relationship with antecedent flow. The relationships between nitrate concentration and Qratio identified in this study serve as the basis for future studies that can better define specific hydrologic processes occurring during and after a drought (or high flow period) which influence nitrate concentration, such as the duration or magnitude of low flows, and the timing of low and high flows.

\section{Introduction}

Many studies show that antecedent moisture conditions influence nutrient export from river basins (Burt and Worrall, 2009; Garrett, 2012; Macrae et al., 2010; Soulsby et al., 2003; Vecchia et al., 2008; Lucey and Goolsby, 1993). Commonly, studies document increased nutrient export following a prolonged dry period (Foster and Walling, 1978; Macrae et al., 2010), though some studies have observed the opposite effect when considering only more recent antecedent conditions (Creed and Band, 1998; Macrae et al., 2010; Welsch et al., 2001). Most observations concerning the influence of antecedent moisture on nutrient export have been made in small basins with generally homogenous land use, land cover, climate, and geology (e.g., Biron et al., 1999; Burt and Worrall, 2009; Cooper et al., 2007; Foster and Walling, 1978; Lange and Haensler, 2012; Macrae et al., 2010; Welsch et al., 2001), and little attention has been given to how this influence plays 
out on a large scale. Yet, the degree to which antecedent moisture affects nutrient export from large basins may have profound implications for environmental management and policy, particularly for large basins in agricultural regions that contribute substantial masses of nutrients to coastal waters. Nutrient fluxes from the Mississippi River basin (MRB) are closely related to the spatial extent of the hypoxic zone in the Gulf of Mexico (Donner and Scavia, 2007; Rabalais and Turner, 2001); consequently, the hypoxic zone is often smaller during a drought when low flows from the Mississippi River deliver smaller nutrient loads to the Gulf (Scavia et al., 2003; Turner et al., 2006). However, nitrate and other nutrients may accumulate within the basin during a drought and be subject to flushing by high flows when a drought ends, resulting in higher than normal nitrate concentrations in receiving waters. Conversely, particularly wet antecedent conditions may flush nitrate and other nutrients from the basin with more frequency, depleting the availability of these constituents in the soil and causing lower than anticipated concentrations in streamwater.

Exploring hydrologic processes, such as the influence of antecedent moisture conditions on nitrate export, in large basins (defined in our study as $>30000$ square kilometers $\left(\mathrm{km}^{2}\right)$ ) is complicated by their diverse mix of land cover, topography, geology and climate, in addition to confounding influences of dams, irrigation, and point and non-point pollution sources. These factors not only hinder the ability to extrapolate results obtained from the investigation of small basins to large basins (Sidle, 2006; Soulsby et al., 2006; Shaman et al., 2004; Sivapalan, 2003) but also make it challenging to use methods typically implemented in small basins, such as the determination of hydrologic storage and flux in soil and groundwater, or direct measurement of flow and concentration from different flow routes (e.g., Rozemeijer et al., 2010). In addition to the diversity of climatic, hydrogeologic, and land use conditions across large basins, there can be substantial spatial variability of precipitation inputs, with some sub-basins experiencing very wet conditions while other sub-basins experience average or even very dry conditions. Since large spatial scales result in highly variable soil water and groundwater storage (spatially and temporally), antecedent moisture conditions in large basins are likely best defined by well-integrated measurement proxies that amalgamate these variable conditions. In this study we use antecedent streamflows at the downstream end of a basin as a proxy for basin-wide antecedent soil moisture.

There are several examples of nutrient studies undertaken in very large basins (e.g., Alexander et al., 2008; Sprague et al., 2011), however, to our knowledge, the relationship between antecedent moisture and nitrate has yet to be explored at a scale as large as the MRB or its major sub-basins. Most hydrologic studies related to antecedent moisture and nitrate have been undertaken at the hillslope scale or in small$\left(<100 \mathrm{~km}^{2}\right)$ and meso-scale (100 to $\left.1000 \mathrm{~km}^{2}\right)$ basins. We identified two studies that cover the largest basin sizes, which

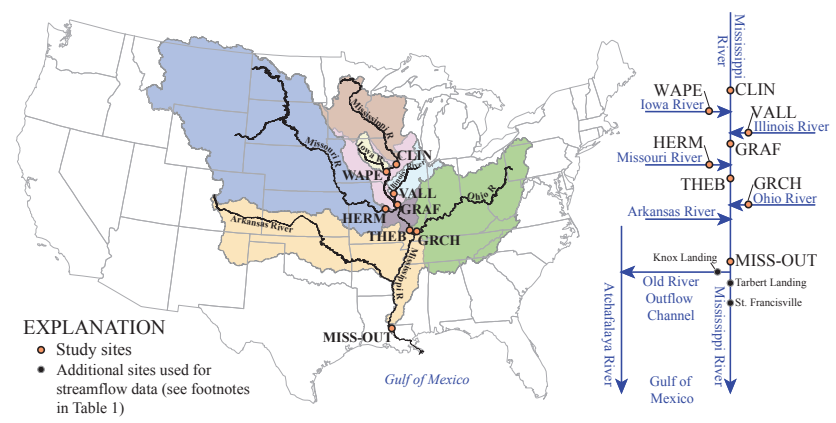

Fig. 1. Map of the continental United States showing Mississippi River basin and study sites, and a schematic line drawing of the relative locations of study sites, major tributaries, and additional sites.

are Vecchia's (2003) study that investigated relationships between other nutrients (ammonia plus organic nitrogen and total phosphorus) and 5-year, 1-year and daily flow anomalies in 30 basins throughout the United States, ranging in size from 114 to $117140 \mathrm{~km}^{2}$, and a study by Lucey and Goolsby (1993) that explored the influence of climatic variations on nitrate in an $8900 \mathrm{~km}^{2}$ basin in Iowa. However, most of the sites in our study are still one or more orders of magnitude larger than even these examples.

Throughout the MRB and other basins in agricultural regions, nitrate accumulates in farm fields due to a variety of influences, including weather conditions, soil characteristics, crop type and yield, fertilizer application, and irrigation (Ferguson et al., 2013; Randall et al., 2003). The timing and interaction of these factors during a period of low precipitation leads to a wide range of nitrogen storage remaining in the soil after a growing season. In general, farms that had an exceptionally low crop yield the previous growing season have elevated soil nitrate concentrations, whereas farms that had average or above-average yields have low soil nitrate concentrations (Sawyer, 2013). During a drought, irrigation is often a determining influence for crop yield and thus the amount of nitrate likely to accumulate in the soil (Sawyer, 2013). Most farmland in the MRB is not irrigated (Table 1) and elevated soil nitrate concentrations are typically anticipated across much of the basin following a drought (Dinnes et al., 2002; Ferguson, et al., 2013; Randall et al., 2003; Rehm et al., 2009; Sawyer, 2013).

In this paper, we explore the relationship between antecedent flows and nitrate anomalies in the MRB and identify which contemporaneous flow conditions exhibit the strongest relationships. Nitrate anomalies are the unexplained variability in nitrate concentration after filtering out season, longterm trend, and contemporaneous flow effects. Our objective is to quantify relationships between antecedent flows and nitrate anomalies for eight sites in the MRB (Fig. 1) using data collected over three decades and across a range of contemporaneous flow conditions. 


\section{Study area description}

Eight sites in the MRB are used in this study, four Mississippi River main-channel sites and four sites in major tributary basins: the Iowa River, Illinois River, Missouri River and Ohio River (Fig. 1). These basins are regional to continental in scale with drainage areas ranging from approximately 32 thousand $\mathrm{km}^{2}$ to over 2.9 million $\mathrm{km}^{2}$ (Table 1). In total, the MRB drains approximately $41 \%$ of the continental United States and is the largest river basin in North America (National Stream Quality Accounting Network; http://water. usgs.gov/nasqan/docs/missfact/missfactsheet.html).

Basin and climate characteristics vary greatly between the eight sites in this study (Table 1). Generally, the Ohio River basin receives the most precipitation, leading to high streamflows and runoff, whereas the Missouri River basin is the driest. The Missouri River basin is also the most hydrologically altered in terms of number of dams and relative storage (Table 1). The smallest basins have the highest percentage of farmland. Basin and climate characteristics also vary widely within each basin. For example, average annual precipitation (1961-1990, The National Atlas; http://www.nationalatlas.gov/) in the northwest portion of the Missouri River basin is approximately 250 millimeters per year $\left(\mathrm{mm} \mathrm{yr}^{-1}\right)$ as compared to $950 \mathrm{~mm} \mathrm{yr}^{-1}$ near the downstream end of the basin, in the vicinity of the Missouri River at Hermann (HERM, Fig. 1). Similarly, in the Ohio River basin, annual precipitation ranges from about $1900 \mathrm{~mm} \mathrm{yr}^{-1}$ in the southeastern portion of the basin to about $950 \mathrm{~mm} \mathrm{yr}^{-1}$ in northern portions of the basin. For the sites in this study, there appears to be a great deal of within-basin variability as well as between-basin variability (described in Table 1) and these variations in basin and climate characteristics add considerable complexity to the identification and interpretation of relationships between antecedent flow and nitrate.

Throughout the MRB, nitrate and other forms of nitrogen in streamwater come from multiple sources including urban runoff, wastewater discharges, atmospheric deposition, and runoff and subsurface flow from agricultural (crop and animal) lands. According to the US Geological Survey's SPARROW (SPAtially Referenced Regression On Watershed attributes) decision support system (Mississippi/Atchafalaya Basin Total Nitrogen Model - 2002; http://cida.usgs.gov/ sparrow/), which models in-stream water quality in relation to upstream sources and basin and climate characteristics, agricultural sources such as fertilizer, waste from confined animals, or legume crops dominate the total nitrogen load to the Gulf of Mexico (MISS-OUT) as compared to atmospheric deposition or population-related sources (Table 2). Furthermore, across all sites the relative proportion of total nitrogen from agriculture is at least 3 times greater than total nitrogen from population-related sources. Contributions of total nitrogen from population-related sources (6 to $22 \%$, depending on the basin) and atmospheric deposition (15 to $32 \%$ ) can be substantial but agriculture (51 to $79 \%$ ) is the

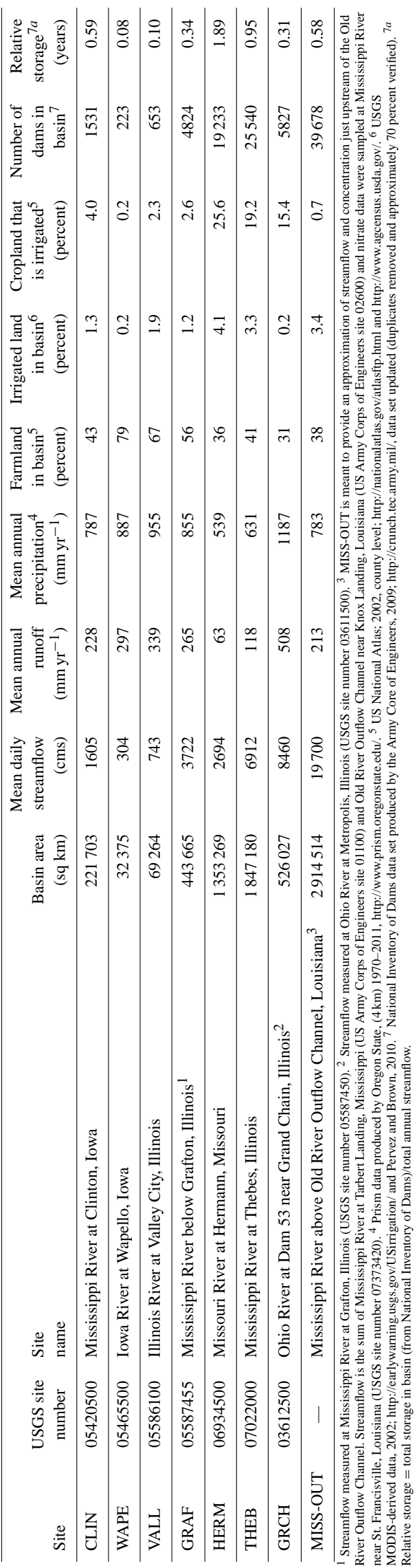

Hydrol. Earth Syst. Sci., 18, 967-979, 2014 
Table 2. Relative contributions of total nitrogen load by source estimated using the SPARROW model (SPAtially Referenced Regression On Watershed attributes) decision support system (Mississippi/Atchafalaya Basin Total Nitrogen Model - 2002; http://cida. usgs.gov/sparrow/).

\begin{tabular}{llrrr}
\hline & & \multicolumn{3}{c}{$\begin{array}{c}\text { Relative contributions of } \\
\text { total nitrogen }\end{array}$} \\
Site & River & $\begin{array}{r}\text { Atmospheric } \\
\text { deposition }\end{array}$ & $\begin{array}{r}\text { Agri- } \\
\text { culture }^{2}\end{array}$ & $\begin{array}{r}\text { Population- } \\
\text { related }^{3}\end{array}$ \\
\hline CLIN & Mississippi & 22 & 68 & 10 \\
WAPE & Iowa & 15 & 79 & 6 \\
VALL & Illinois & 15 & 64 & 22 \\
GRAF & Mississippi & 18 & 71 & 11 \\
HERM & Missouri & 21 & 69 & 10 \\
THEB & Mississippi & 19 & 69 & 12 \\
GRCH & Ohio & 32 & 51 & 18 \\
MISS-OUT & Mississippi & 25 & 61 & 14 \\
\hline
\end{tabular}

${ }^{1}$ May not sum to 100 due to independent rounding. ${ }^{2}$ Includes fertilizer, waste from confined animals and legume crops. ${ }^{3}$ Includes wastewater treatment plants and urban sources.

dominant source of total nitrogen for the eight basins in this study (Table 2).

\section{Data compilation}

The eight sites used in this study (Table 1) are a part of a network of long-term data-collection sites throughout the United States that are maintained by the US Geological Survey (USGS) through the National Water-Quality Assessment (NAWQA) and National Stream-Quality Accounting Network (NASQAN) Programs. Streamflow and dissolved nitrate plus nitrite concentrations (referred to as nitrate hereafter) were compiled and prepared for each site according to the techniques outlined in Aulenbach et al. (2007). Daily mean streamflow data used in this study are from 1979 through the fall of 2011. Nitrate data were compiled from samples collected between 1980 and the fall of 2011 on a semi-monthly to monthly frequency (e.g., 9-18 samples per year). Nitrate data were collected across a range of streamflow conditions, including base and peak flows.

\section{Methods}

In the main channel of the Mississippi River and in several of its major tributaries, nitrate concentrations have been related to season, long-term trend over time, and contemporaneous daily mean flow (Sprague et al., 2011). A portion of the remaining unexplained variability in nitrate concentration may be related to antecedent flow conditions. In this study, a statistical model is used to quantify the unexplained variability in nitrate concentration after filtering out these effects. This unexplained variability is the deviation of the observed log nitrate concentration from the log nitrate concen-

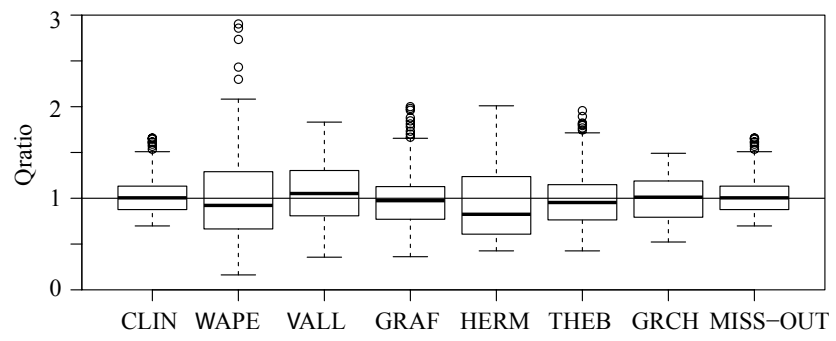

Fig. 2. Box plot of Qratio values by site.

tration predicted by a statistical model (based on contemporaneous daily mean flow, season, and trend), herein referred to as nitrate anomalies (Vecchia et al., 2008). To evaluate if antecedent flow conditions can help to explain variations in nitrate concentrations, we tested whether nitrate anomalies were significantly (alpha $=0.05$ ) related to a measure of antecedent flow conditions.

In this study, we define antecedent flow as a ratio between mean daily flow of the previous year and mean daily flow of the period of record, for a given site $\left(Q_{\text {ratio }}\right)$. The $Q_{\text {ratio }}\left(\mathrm{Qr}_{i}\right)$ for day $i$ is calculated as

$\mathrm{Qr}_{i}=\frac{\mathrm{Qyr}_{i}}{Q_{\mathrm{POR}}}$,

where $\mathrm{Qyr}_{i}$ is the mean daily flow for the previous year (day $i$ through the previous 364 days), and QPOR is the mean daily flow for the period of record. Qratio values greater than 1 indicate higher than average mean daily flows for the previous year; values less than 1 indicate lower than average flows. Qratios for the eight sites used in our study range from 0.16 to 2.90 and the majority are within \pm 0.25 of 1 (Fig. 2).

By using streamflow integrated over the year as a largebasin surrogate for the kinds of hydrologic storage and flux measures that might be used in small-basin-process models, we are able to acquire a general measure of basin moisture that is likely related to other physical, chemical and biological processes in a basin that are affected by preceding moisture conditions. The choice of a one-year averaging period used to compute the Qratio makes this antecedent flow measure independent of the time of year and season. It is possible that more complex statistical formulations with seasonal terms or an averaging period other than one year would have a stronger statistical association with nitrate anomalies, but model parsimony led us to commit to this simpler formulation. Using Qratio to describe antecedent flows characterizes hydrologic conditions broadly and allows for an initial examination of how nitrate concentration responds following a drought or high flow period. If significant relationships are documented, future studies can help better define the specific hydrologic processes that influence nitrate concentration during and after a drought or high flow period.

We used the published Weighted Regressions on Time, Discharge, and Season model (WRTDS; Hirsch et al., 2010) 
to determine nitrate anomalies. WRTDS uses time, contemporaneous flow, and seasonal variables to estimate solute concentrations for large river basins that have several decades of flow and concentration data. Locally weighted regression is used to make unbiased estimates of the log of nitrate concentration for each day (Hirsch et al., 2010). WRTDS was used to estimate nitrate concentration from 1980 through the fall of 2011 for the eight sites in this study. The residuals from this modeling effort are the nitrate anomalies analyzed in this study. Predicted log nitrate concentration $\left(\mathrm{pc}_{i}\right)$ for day $i$ is modeled in WRTDS as

$\mathrm{pc}_{i}=\beta_{0}+\beta_{1} t+\beta_{2} \ln (Q)+\beta_{3} \sin (2 \pi t)+\beta_{4} \cos (2 \pi t)$,

where $\ln$ is the natural $\log , \beta_{0}, \beta_{1}, \ldots, \beta_{4}$ are fitted coefficients, $t$ is time, and $Q$ is daily mean streamflow (Hirsch et al., 2010). Nitrate anomaly $\left(\mathrm{CA}_{i}\right)$ for day $i$ is defined as

$\mathrm{CA}_{i}=\ln \left(c_{i}\right)-\mathrm{pc}_{i}$

where $c_{i}$ is the observed nitrate concentration on day $i$, and $\mathrm{pc}_{i}$ is the predicted log nitrate concentration on day $i$. By using WRTDS, nitrate anomalies can be conceptualized as the portion of the concentration signal that is not accounted for by contemporaneous discharge, season or long-term trend. Since nitrate anomalies are simply the residuals from the model these values represent a combination of measurement error, inadequacies of the model's functional form, estimation error of the coefficients, and the influence of other variables that are not considered by the model. In this case, we explicitly consider the role that antecedent streamflow, a variable not included in the model, might play. Thus, a positive nitrate anomaly indicates higher-than-anticipated observed concentration; a negative anomaly indicates a lower-thananticipated observed concentration. For details on WRTDS and the modeling of nitrate concentration at these sites, see Hirsch et al. (2010) and Sprague et al. (2011).

Nonparameteric statistical methods were used to explore relationships between antecedent flows and nitrate anomalies because the Qratio data are positively skewed and contain outliers (Fig. 2). The strength of the correlation between nitrate anomaly and Qratio was determined using Kendall's tau, and the relationship was quantified using the KendallTheil robust line (Helsel and Hirsch, 2002). The robust line describes the response of nitrate anomaly to Qratio and is defined as

$\mathrm{CA}_{i}=\beta_{0}+\beta_{1} \cdot \mathrm{Qr}_{i}$,

where $\mathrm{CA}_{i}$ is the nitrate anomaly for day $i, \mathrm{Qr}_{i}$ is the Qratio on day $i$, and $\beta_{0}$ and $\beta_{1}$ are the fitted coefficients for the intercept and slope, respectively. Rather than using ordinary least squares to estimate the coefficients, the slope is based on the median slope of all pairwise slopes between $\mathrm{CA}_{i}$ and $\mathrm{Qr}_{i}$ values, and the intercept is back-calculated using this median slope and a point defined by the median of all $\mathrm{CA}_{i}$ values and
Table 3. Kendall's tau and robust line results of nitrate anomaly and Qratio relationships, using all contemporaneous flow data. Statistically significant relationships $(p<=0.05)$ are italicized $[n$, number of observations].

\begin{tabular}{llrrrrr}
\hline Site & River & Tau & $p$ value & Intercept & Slope & $n$ \\
\hline CLIN & Mississippi & -0.13 & $<0.01$ & 0.60 & -0.48 & 315 \\
WAPE & Iowa & -0.15 & $<0.01$ & 0.29 & -0.20 & 312 \\
VALL & Illinois & -0.17 & $<0.01$ & 0.22 & -0.18 & 370 \\
GRAF & Mississippi & -0.03 & 0.50 & 0.10 & -0.05 & 308 \\
HERM & Missouri & 0.06 & 0.06 & -0.03 & 0.12 & 429 \\
THEB & Mississippi & -0.05 & 0.09 & 0.12 & -0.09 & 431 \\
GRCH & Ohio & -0.16 & $<0.01$ & 0.37 & -0.34 & 378 \\
MISS-OUT & Mississippi & -0.05 & 0.15 & 0.16 & -0.12 & 401 \\
\hline
\end{tabular}

the median of all $\mathrm{Qr}_{i}$ (Helsel and Hirsch, 2002). Robust lines were fit for each site using all available data.

Additionally, to identify the contemporaneous flow conditions in which concentrations are most sensitive to antecedent flows, data at each site were divided into flow classes according to the daily mean flow on the day of sample collection, and robust lines were fit to each site and flow class. Contemporaneous flow classes consist of four percentile ranges based on the observed streamflow across the period of record: low $(<25$ th percentile), midlow ( $>25$ th and $<50$ th percentile), mid-high $(>50$ th and $<75$ th percentile), and high ( $>75$ th percentile) contemporaneous flows.

Finally, to quantify the effect of antecedent flow on nitrate concentration, as opposed to nitrate anomaly, the percent difference in nitrate concentration relative to a previous year that had average mean daily flow $($ Qratio $=1)$ was determined using the following equation:

Percent difference in concentration $=\left(\frac{\exp \left(\beta_{1} \cdot \mathrm{Qr}_{i}\right)}{\exp \left(\beta_{1}\right)}-1\right) \cdot 100$

where $\beta_{1}$ is the slope coefficient for a given site and flow class. Because the denominator in Eq. (5) gives the expected nitrate concentration following a year with average flow conditions, the resulting percent difference from this equation gives the anticipated increase or decrease in nitrate concentration for a given antecedent flow condition $\left(\mathrm{Qr}_{i}\right)$ relative to nitrate concentration following a year with average antecedent flow conditions. Four hypothetical Qratio values $\left(\mathrm{Qr}_{i}=0.5,0.75,1.25\right.$ and 1.5) were applied using Eq. (5) at each site and flow class. These results will parallel those quantified by the robust line relationships (Eq. 4), but apply directly to nitrate concentration instead of nitrate anomaly.

\section{Results and discussion}

\subsection{Nitrate anomaly and antecedent flow across all contemporaneous flows}

When all contemporaneous flows at each site are considered together, the upper Mississippi River (CLIN) and the 

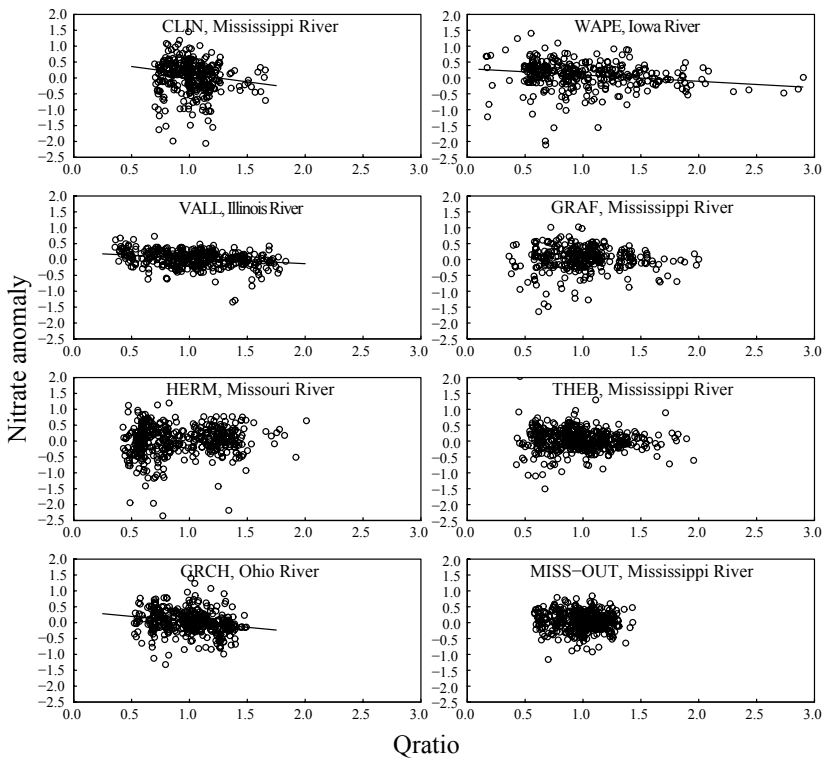

Fig. 3. Plots of nitrate anomaly versus Qratio by site, using all contemporaneous flow data. Statistically significant relationships $(p \leq 0.05)$ are denoted with a solid black line.

major tributaries (WAPE, VALL, and GRCH), except the Missouri River (HERM), exhibit statistically significant relationships $(p \leq 0.05)$ between Qratio and nitrate anomaly (Fig. 3), though tau is small, ranging from -0.13 to -0.17 depending on the site (Table 3). All sites have negative slopes and the steepest slope occurred in the upper Mississippi River (CLIN). Downstream Mississippi River sites (GRAF, THEB, and MISS-OUT) and the Missouri River (HERM) do not demonstrate significant relationships across the observed range of flows (Fig. 3). Note that all three basins larger than 1 million $\mathrm{km}^{2}$ had non-significant correlations but four out of the five basins smaller than 1 million $\mathrm{km}^{2}$ had significant correlations. In general, the relationships between antecedent flow and nitrate shown here are weak to moderately strong with low to moderate correlation (Table 3), which is not necessarily surprising given the complexity of solute behavior in large basins (Webb and Walling, 1984).

To describe the potential response of nitrate concentration to different antecedent flow conditions, four Qratio values $\left(\mathrm{Qr}_{i}=0.50,0.75,1.25\right.$ and 1.50) were applied using Eq. (5) at the sites with significant robust line relationships $(p \leq 0.05$, Table 3). At the two smallest tributary sites (WAPE and VALL) when the previous year's flow is 50 percent higher or lower than average $\left(\mathrm{Qr}_{i}=1.5\right.$ or 0.5 , respectively) nitrate concentration is about 10 percent lower or higher than expected, respectively (Table 4). These positive or negative differences in nitrate concentration are relative to the nitrate concentration that follows a (hypothetical) year that had average mean daily flow $\left(\mathrm{Qr}_{i}=1.0\right)$. In the upper Mississippi River (CLIN) and Ohio River (GRCH), the difference in nitrate concentration could be as much as 27 percent higher or 21 percent lower than expected when the previous year's flow is 50 percent lower or higher than average, respectively. At these same sites, nitrate concentration could be only about \pm 10 percent different than expected when the previous year's flow deviates about 25 percent from average flow conditions (Table 4). Therefore, the influence of antecedent flow conditions on nitrate concentration may be twice as strong at the sites with slightly larger basin areas (CLIN and GRCH), as compared to the sites with the smallest basin areas in our study (WAPE and VALL).

In this analysis, the Qratio describes previous flow conditions in a basin and also serves as a proxy for changes to other physical, chemical and biological processes that are affected by inter-annual variation in the overall moisture of a basin. Grouped into two broad categories, variations in antecedent flow conditions often coincide with changes to (1) the mass and availability of nitrate in soil (supply), and (2) hydrologic processes that move nitrate through the basin to the stream (transport). Many processes control the accumulation of available nitrate in the soil during a drought, and most are closely related to soil moisture conditions. These may include increased plant stress resulting in low nitrate uptake and low crop yields (Groves and Bailey, 1997), decreased microbial processes resulting in more limited denitrification (Ashby et al., 1998; de Klein and van Logtestijn, 1996) and decreased runoff and leaching (Emmerich and Heitschmidt, 2002; Stites and Kraft, 2001). The timing of fertilizer application before or after a rainfall or irrigation event also influences the amount of available nitrate in the soil (Aulakh and Bijay-Singh, 1997). Additionally, droughts and periods of low flow typically coincide with lowered water tables, decreased hydrologic storage, and decreased hydrologic connectivity, all of which inhibit nitrate transport to streams (Bernal and Sabater, 2012; Detty and McGuire, 2010; Macrae et al., 2010). Wetter antecedent conditions can cause these supply- and transport-limiting processes to have the opposite effect of minimizing the accumulation of nitrate in the soil through denitrification, crop uptake and other processes, while also increasing hydrologic connectivity and the frequency with which nitrate is transported to groundwater or a stream. Although supply- and transport-limiting processes interact to encourage or inhibit nitrate export, the varying influence of these processes can result in inconsistent relationships between antecedent flow conditions and nitrate concentration among different basins (Macrae et al., 2010) and even over time within a single basin (Burt and Worrall, 2009, 2007).

The statistically significant negative relationships $(p \leq 0.05)$ between Qratio and nitrate anomaly (Fig. 3) exhibited in the upper Mississippi River (CLIN), Iowa River (WAPE), Illinois River (VALL) and Ohio River (GRCH) indicate that below-average mean daily streamflow the previous year relates to higher nitrate anomalies (and concentrations), and above-average mean daily flow the previous year relates to lower nitrate anomalies (and concentrations). 
Table 4. Percent difference in nitrate concentration relative to nitrate concentration expected following a year with average flow conditions (see Eq. 5). Positive and negative percent differences describe the increase or decrease of nitrate concentration, respectively, in response to four hypothetical antecedent flow conditions. Qratio scenarios describe when mean daily streamflow the previous year was 50 and 25 percent lower than average (Qratios 0.50 and 0.75 , respectively) and 25 and 50 percent higher than average (Qratios 1.25 and 1.50 , respectively). These scenarios are only applied to relationships that were statistically significant $(p<=0.05)$.

\begin{tabular}{|c|c|c|c|c|c|c|c|c|c|c|c|c|c|c|c|c|c|c|c|c|c|}
\hline \multirow[b]{3}{*}{ Site } & \multirow[b]{3}{*}{ River } & \multicolumn{4}{|c|}{$\begin{array}{l}\text { All contemporaneous } \\
\text { flow conditions }\end{array}$} & \multicolumn{4}{|c|}{$\begin{array}{l}\text { Low flow } \\
\text { conditions }\end{array}$} & \multicolumn{4}{|c|}{$\begin{array}{l}\text { Mid-low flow } \\
\text { conditions }\end{array}$} & \multicolumn{4}{|c|}{$\begin{array}{l}\text { Mid-high flow } \\
\text { conditions }\end{array}$} & \multicolumn{4}{|c|}{$\begin{array}{l}\text { High flow } \\
\text { conditions }\end{array}$} \\
\hline & & \multicolumn{4}{|c|}{ Drier (Qratio) Wetter } & \multicolumn{4}{|c|}{ Drier (Qratio) Wetter } & \multicolumn{4}{|c|}{ Drier (Qratio) Wetter } & \multicolumn{4}{|c|}{ Drier (Qratio) Wetter } & \multicolumn{4}{|c|}{ Drier (Qratio) Wetter } \\
\hline & & 0.5 & 0.75 & 1.25 & 1.5 & 0.5 & 0.75 & 1.25 & 1.5 & 0.5 & 0.75 & 1.25 & 1.5 & 0.5 & 0.75 & 1.25 & 1.5 & 0.5 & 0.75 & 1.25 & 1.5 \\
\hline & & \multicolumn{4}{|c|}{ (percent change) } & \multicolumn{4}{|c|}{ (percent change) } & \multicolumn{4}{|c|}{ (percent change) } & \multicolumn{4}{|c|}{ (percent change) } & \multicolumn{4}{|c|}{ (percent change) } \\
\hline CLIN & Mississippi & 27 & 13 & -11 & -21 & & & & & & & & & & & & & 34 & 16 & -14 & -26 \\
\hline WAPE & Iowa & 10 & 5 & -5 & -9 & & & & & & & & & & & & & 13 & 6 & -6 & -12 \\
\hline VALL & Illinois & 9 & 5 & -4 & -8 & & & & & & & & & 19 & 9 & -8 & -16 & 13 & 6 & -6 & -11 \\
\hline GRAF & Mississippi & & & & & & & & & & & & & & & & & & & & \\
\hline HERM & Missouri & & & & & & & & & & & & & -16 & -8 & 9 & 19 & & & & \\
\hline THEB & Mississippi & & & & & & & & & & & & & 11 & 6 & -5 & -10 & & & & \\
\hline GRCH & Ohio & 19 & 9 & -8 & -16 & 44 & 20 & -17 & -30 & 19 & 9 & -8 & -16 & 15 & 7 & -7 & -13 & & & & \\
\hline MISS-OUT & Mississippi & & & & & 20 & 9 & -9 & -17 & & & & & & & & & & & & \\
\hline
\end{tabular}

At these sites, it appears soil nitrate that accumulates during dry periods increases the supply of nitrate, which may influence nitrate export later in the year. The remaining sites further downstream on the Mississippi River (GRAF, THEB and MISS-OUT) and the Missouri River (HERM) do not provide evidence that nitrate anomalies are related to antecedent flow conditions, at least when considering all contemporaneous flows together. Interestingly, the GRAF site, located on the Mississippi River below the confluence with the Illinois River (Fig. 1), has relatively similar climate and basin characteristics as CLIN, WAPE and VALL (Table 1), yet does not show a statistically significant relationship between Qratio and nitrate anomaly when all contemporaneous flows are considered.

The lack of an apparent relationship at HERM, THEB or MISS-OUT is not necessarily surprising given that these sites have drainage areas in excess of 1 million $\mathrm{km}^{2}$ whereas other sites have drainage areas less than $600000 \mathrm{~km}^{2}$. The diversity of basin characteristics in the drainage area above HERM, THEB and MISS-OUT is very substantial and the Qratio is likely a poor indicator of the moisture status of the particular areas in these basins that are major contributors of nitrate to streamwater. For example, during the 2011 Missouri River flood the upper reaches of the basin provided most of the flood water and this area has very limited row crop agriculture, thus the water delivered to streams in this region had relatively low concentrations of nitrate; however, most high flow events in the Missouri River basin tend to originate in lower portions of the basin that are highly agricultural and deliver relatively high concentrations of nitrate to streams (Kalkhoff, 2013). Further complicating factors include lag times associated with groundwater discharges (Sanford and Pope, 2013) and the travel time of water through basins (Krichner et al., 2001) and large river networks. For example, at the outflow of the Mississippi River (MISS-OUT), streamwater from different locations in the MRB can take weeks to months to reach MISS-OUT (Nolan et al., 2002), thus the relationships between antecedent flows and nitrate anomalies observed upstream in more homogenous tributaries are likely smeared as water moves downstream and mixes with water from other sources. Also, transport processes in some basins have been found to be more dependent on the permeability and storage capacity of the soil and bedrock as compared to other basins where flow-path lengths and the density of drainage networks are important influences (Hrachowitz et al., 2013).

\subsection{Nitrate anomaly and antecedent flow by contemporaneous flow class}

In most cases, the relationship between Qratio and nitrate anomaly is stronger when the flow condition on the day of sample collection (contemporaneous flow) is considered. Robust line coefficients and tau are typically greater in magnitude for specific contemporaneous flow classes (Table 5) as compared to those derived using all contemporaneous flow data together (Table 3).

\subsubsection{Relationships at mid-high and high contemporaneous flows}

At the highest contemporaneous flows ( $>75$ th percentile) Qratio and nitrate anomaly are negatively related $(p \leq 0.05)$ at three (CLIN, WAPE and VALL) of the eight sites (Table 5). Also, at mid-high contemporaneous flows (> 50th and $<75$ th percentile), nitrate anomalies are negatively related to the Qratio at three of the eight sites (VALL, THEB and GRCH) and positively related at one site (HERM). In total, six of the eight sites (including GRAF, though the relationship is not statistically significant $(p=0.06)$ ) show negative relationships between Qratio and nitrate anomaly when contemporaneous flows were greater than the 50th percentile of flow (Fig. 4), suggesting a flushing response occurs during elevated flows that follow extended dry antecedent conditions. Flushing responses during storm events have been explored 
Table 5. Kendall's tau and robust line results of nitrate anomaly and Qratio relationships, by contemporaneous flow class. Statistically significant values ( $p<=0.05$ ) are italicized [daily $\mathrm{Q}$, daily streamflow; Interc, intercept; $n$, number of observations].

\begin{tabular}{|c|c|c|c|c|c|c|c|c|c|c|c|c|c|c|c|c|c|c|c|c|c|}
\hline \multirow[b]{2}{*}{ Site } & \multirow[b]{2}{*}{ River } & \multicolumn{5}{|c|}{$\begin{array}{l}\text { Low flow conditions } \\
\text { (daily } \mathrm{Q}<25 \text { th) }\end{array}$} & \multicolumn{5}{|c|}{$\begin{array}{l}\text { Mid-low flow conditions } \\
(25 \text { th }<\text { daily } \mathrm{Q}<50 \text { th) }\end{array}$} & \multicolumn{5}{|c|}{$\begin{array}{l}\text { Mid-high flow conditions } \\
\text { (50th < daily } \mathrm{Q}<75 \text { th) }\end{array}$} & \multicolumn{5}{|c|}{$\begin{array}{l}\text { High flow conditions } \\
\text { (daily } Q>75 \text { th) }\end{array}$} \\
\hline & & Tau & $p$ value & Interc & Slope & $n$ & Tau & $p$ value & Interc & Slope & $n$ & Tau & $p$ value & Interc & Slope & $n$ & Tau & $p$ value & Interc & Slope & $n$ \\
\hline CLIN & Mississippi & -0.09 & 0.46 & 0.57 & -0.51 & 39 & -0.06 & 0.49 & 0.40 & -0.26 & 60 & -0.11 & 0.12 & 0.57 & -0.45 & 93 & -0.18 & $<0.01$ & 0.71 & -0.59 & 122 \\
\hline WAPE & Iowa & -0.09 & 0.29 & 0.22 & -0.32 & 58 & -0.14 & 0.09 & 0.30 & -0.20 & 65 & -0.12 & 0.08 & 0.29 & -0.15 & 91 & -0.20 & $<0.01$ & 0.36 & -0.25 & 96 \\
\hline VALL & Illinois & -0.07 & 0.34 & 0.13 & -0.10 & 79 & -0.05 & 0.58 & 0.08 & -0.05 & 70 & -0.34 & $<0.01$ & 0.42 & -0.34 & 94 & -0.25 & $<0.01$ & 0.31 & -0.24 & 125 \\
\hline GRAF & Mississippi & 0.09 & 0.31 & -0.10 & 0.23 & 63 & 0.12 & 0.12 & -0.12 & 0.23 & 78 & -0.14 & 0.06 & 0.26 & -0.21 & 81 & -0.11 & 0.13 & 0.15 & -0.16 & 85 \\
\hline HERM & Missouri & 0.10 & 0.14 & -0.29 & 0.53 & 98 & 0.04 & 0.54 & 0.09 & 0.10 & 105 & 0.19 & $<0.01$ & -0.35 & 0.35 & 103 & -0.02 & 0.71 & 0.08 & -0.05 & 123 \\
\hline THEB & Mississippi & 0.01 & 0.86 & 0.01 & 0.03 & 85 & -0.08 & 0.23 & 0.17 & -0.16 & 93 & -0.12 & 0.05 & 0.26 & -0.21 & 115 & -0.08 & 0.18 & 0.18 & -0.11 & 130 \\
\hline GRCH & Ohio & -0.20 & $<0.01$ & 0.70 & -0.73 & 87 & -0.16 & 0.04 & 0.41 & -0.35 & 79 & -0.17 & $<0.01$ & 0.28 & -0.29 & 111 & -0.11 & 0.12 & 0.20 & -0.16 & 101 \\
\hline MISS-OUT & Mississippi & -0.14 & 0.05 & 0.38 & -0.36 & 91 & -0.02 & 0.77 & 0.12 & -0.06 & 84 & -0.06 & 0.34 & 0.20 & -0.14 & 109 & 0.02 & 0.69 & -0.06 & 0.06 & 115 \\
\hline
\end{tabular}

extensively in the literature for small forested and agricultural basins (Biron et al., 1999; Burt et al., 1988; Foster and Walling, 1978; Hornberger et al., 1994; Macrae et al., 2010; Walling and Foster, 1975), and is primarily attributed to the rapid movement of nitrate during a storm when the water table intersects soil horizons that have accumulated elevated stocks of nitrate during periods of low moisture. Our results suggest that a flushing response, previously documented for small, relatively homogenous basins during storms, is also observable at a regional scale during elevated streamflows. Conversely, at these sites above-average mean daily flow the previous year relates to lower nitrate anomalies during midhigh and high flows, possibly because the mass of stored nitrate has been depleted by increased export from the basin and uptake by plants earlier in the year. Noticeably, the flushing response at the highest flows ( $>75$ th percentile) is evident only for the smallest basins $\left(<250000 \mathrm{~km}^{2}\right)$ and no statistically significant relationships occur at the highest flows for basins larger than $250000 \mathrm{~km}^{2}$ (Fig. 4). With the exception of GRAF (Fig. 1), these smaller basins (CLIN, WAPE and VALL) have the highest percentage of farmed land (Table 1), which suggests that during high flows, dilution from an expanding variable source area with low nitrate concentrations likely obscures the influence of antecedent flow conditions (Creed and Band, 1998) in larger study basins, whereas dilution in smaller, more intensely farmed basins appears less common.

Contrary to other sites in the MRB, nitrate anomaly is positively related to the Qratio in the Missouri River (HERM) during mid-high contemporaneous flows (Fig. 4). This observation directly contradicts the flushing response model described for other sites. However, higher antecedent flow conditions have been related to increased nitrate export in other studies, though in these studies antecedent conditions were typically considered over time periods shorter than a year and in basins smaller than those considered in this study (e.g., Welsch et al., 2001; Macrae et al., 2010). Additionally, of all the basins in this study, the Missouri River is considered the most heterogeneous; the variation in weather and terrain throughout this basin can cause parts of the Missouri River to experience markedly different hydrologic conditions simultaneously.
A possible explanation for this relationship in the Missouri River (HERM) is that the supply of exportable nitrate during a drought is reduced by irrigation. Approximately 25 percent of cropland in the Missouri River basin is irrigated, making it the most irrigated basin in this study (Table 1). During droughts, irrigation may remove nitrate from the soil horizon by leaching, denitrification, or uptake by crops (Aulakh and Bijay-Singh, 1997; Dinnes et al., 2002). Leached nitrate typically moves downward below the active root zone, leading to elevated nitrate concentrations in groundwater (Burkart and Stoner, 2008; Stites and Kraft, 2001). Increased denitrification occurs with irrigation because elevated soil moisture conditions increase microbial activity (de Klein and van Logtestijn, 1996; Groves and Bailey, 1997). Which process dominates during a drought is debatable and may depend on soil properties, fertilizer application rates, and climate (Aulakh and Bijay-Singh, 1997; Brown et al., 2011). In the Missouri River basin, a recent modeling effort found that increases in irrigation relate to decreases in total nitrogen export on a regional scale (Brown et al., 2011). Irrigation likely occurs at a higher rate when the weather is drier than average, according to a study in Illinois (Bowman and Collins, 1987), therefore, lower nitrate anomalies in the Missouri River (HERM) following a drought may occur because processes associated with irrigation do not allow for the accumulation of nitrate in soil during drier-than-average climatic conditions. However, the supply-limiting influence of irrigation does not account for the higher nitrate anomalies observed following a year with higher antecedent flows.

Interestingly, the Missouri River basin also has the greatest number of dams and the highest relative storage of any basin (Table 1). The reservoirs in this basin hold approximately 1.89 times the annual flow of the Missouri River at HERM, which is more than twice the relative storage of any other site in this study (Table 1). Therefore, flow conditions at HERM, and low flows in particular, are not just the result of natural hydrologic conditions but are also influenced by release decisions made by dam operators. The confounding processes of irrigation and dam storage in addition to the geophysical and climatological heterogeneity of the Missouri River basin make even rudimentary interpretation problematic. 

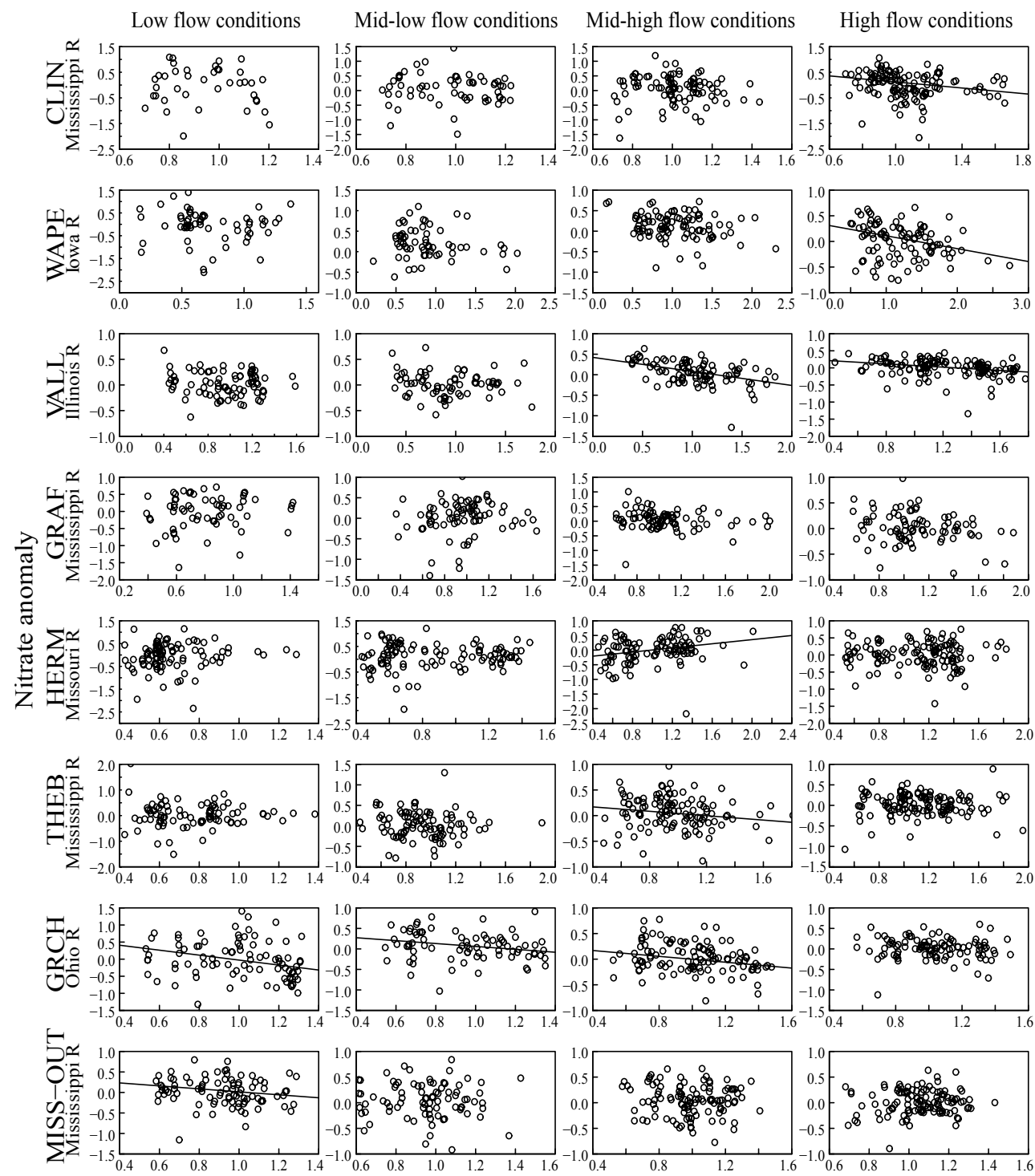

Qratio

Fig. 4. Plots of nitrate anomaly versus Qratio, by site and contemporaneous flow class. Statistically significant relationships $(p \leq 0.05)$ are denoted with a solid black line. Low flow conditions: $<25$ th percentile, mid-low flow conditions: $>25$ th and $<50$ th percentile, mid-high flow conditions: $>$ 50th and $<75$ th percentile, and high flow conditions: $>75$ th percentile. Note horizontal and vertical axes are specific to each plot.

For the six sites with significant robust line relationships at mid-high or high ( $>50$ th percentile) contemporaneous flow classes ( $p \leq 0.05$, Table 5) four Qratio values $\left(\mathrm{Qr}_{i}=0.5\right.$, $0.75,1.25$ and 1.5) were applied using Eq. (5) to describe the potential response of nitrate concentration to different antecedent flow conditions. When the previous year's flow is 25 percent lower than average $\left(\mathrm{Qr}_{i}=0.75\right)$, nitrate concentration may be about 6 to 9 percent higher than expected, for most sites where nitrate anomaly is negatively related to the Qratio (Table 4). Nitrate concentration increases to about 11 to 19 percent, different from expected when the previous year's flow is 50 percent lower than average $\left(\mathrm{Qr}_{i}=0.50\right)$. Nitrate concentration appears to be more sensitive to antecedent flow conditions during high contemporaneous flows in the upper Mississippi River (CLIN); when flows the previous year were 25 to 50 percent lower than average, nitrate concentration can be 16 to 34 percent higher than expected (Table 4). At these sites, differences in nitrate concentration are slightly smaller in magnitude and lower than expected when the previous year had higher-than-average flows (Table 4). In the Missouri River, percent differences in nitrate concentration are similar in magnitude to those at other sites but opposite 
in direction; when flows the previous year were 25 to 50 percent lower than average, nitrate concentration is 8 to 16 percent lower than expected, respectively. With the exception of HERM, these patterns are consistent with the conceptual model of soil nitrate flushing during high and mid-high flows following a drought.

\subsubsection{Relationships at mid-low and low contemporaneous flows}

Only the Ohio River (GRCH) and Mississippi outflow (MISS-OUT) demonstrate a significant negative response $(p \leq 0.05)$ to the previous year's flow at mid-low $(>25$ th and $<50$ th percentile) or low $(<25$ th percentile) contemporaneous flows (Fig. 4, Table 5). Other studies of meso-scale basins $\left(<1000 \mathrm{~km}^{2}\right)$ have found that, when not considering storm flows, inter-annual variations in climate act as a hydrologic driver that influences the mixing of groundwater with different residence times (but rather stable nitrate concentration) resulting in variations of nitrate concentration and flux in streamwater (Gascuel-Odoux et al., 2010). In this context, the significant relationships during mid-low and low contemporaneous flows suggest the groundwater systems for GRCH and MISS-OUT may be influenced by annual variations in surface conditions or climate. However, the age of groundwater discharge to large rivers can be highly variable depending on geology, terrain and soil characteristics (Sanford and Pope, 2013). Throughout the MRB, the lack of statistically significant (Table 5) or visually strong (Fig. 4) relationships between antecedent flow and nitrate anomaly at mid-low and low contemporaneous flows may simply indicate that there is no overland flow flushing the stored nitrate to the river during these flow conditions. However, it may also imply that surface runoff (overland flow) and shallow groundwater with residence times less than one year are likely the main pathways influenced by antecedent flow conditions. To better capture the influence of preceding moisture conditions on nitrate export during low and mid-low flows, multi-year metrics of antecedent flows (or moisture conditions) may be needed.

Using Eq. (5) and four Qratio values $\left(\mathrm{Qr}_{i}=0.5,0.75,1.25\right.$ and 1.5) to translate nitrate anomalies to nitrate concentration, it appears that nitrate concentration is more sensitive to changes in antecedent flow during low and mid-low contemporaneous flows in the Ohio River (GRCH) and Mississippi outflow (MISS-OUT) than during high and mid-high flows at most other sites (Table 4). However, while the relationships between Qratio and nitrate anomaly at mid-low and low flows at GRCH and MISS-OUT are statistically significant ( $p \leq 0.05$ ), they do not appear as visually strong as those at other sites or higher contemporaneous flow conditions (Fig. 4). For mid-low and low flow classes, when the previous year's flow is 25 percent lower than average $\left(\mathrm{Qr}_{i}=0.75\right)$, nitrate concentration may be about 9 to 20 percent greater than expected. As antecedent flow conditions become in- creasingly low (50 percent of average flow, $\left.\mathrm{Qr}_{i}=0.50\right)$ nitrate concentration can be 19 to 44 percent higher than expected (Table 4). Similarly, during mid-low or low contemporaneous flow conditions when the previous year's flow is 25 percent and 50 percent higher than average $\left(\mathrm{Qr}_{i}=1.25\right.$ and 1.50 , respectively), nitrate concentration can be between 8 and 30 percent lower than expected at GRCH and MISSOUT (Table 4).

\section{Conclusions}

Many of the sites in our study, except the Missouri River (HERM), show a negative relationship between antecedent flow conditions and nitrate anomaly when specific contemporaneous flow classes are considered, or when all contemporaneous flows are considered together, suggesting that the influence of antecedent moisture conditions on nitrate export is observable at a large scale. The higher-than-expected nitrate concentrations that occur if streamflow during the previous year was lower than average likely are due to the accumulation of soil nitrate during a drought, and subsequent flushing with moderately high to high flows when the drought ends. Conversely, when the previous year's flow was higher than average, lower nitrate concentrations possibly occur because more nitrate is likely taken up by crops, removed from the system through denitrification, or transported with greater frequency (at lower concentrations) to the stream and groundwater earlier in the year. The positive relationship observed in the Missouri River (HERM) during mid-high contemporaneous flow conditions indicates relationships between antecedent flow and nitrate anomaly not only vary by contemporaneous flow class and basin size, but also regionally. How higher-than-expected nitrate concentrations following a drought will affect the hypoxic zone in the Gulf of Mexico is debatable, and is likely influenced by factors such as the timing of delivery to the Gulf (during the spring versus the fall, for example), the magnitude of flows transporting nitrate through the basin, the spatial and temporal variability of sub-basins experiencing drought and flushing, and changes to nutrient management practices throughout the basin.

In this study we identified significant relationships between antecedent flow conditions and nitrate concentration for regional-scale basins and propose several questions to encourage future studies on this topic at similar scales.

- What are the controlling influences for relationships between antecedent flow conditions and nutrient export, and how do these relationships change based on climate, basin characteristics, and management practices? 
- Do relationships between antecedent flows and nitrate export change over time, as documented in other basins with long temporal records (Burt and Worrall, 2009; Burt and Worall, 2007)?

- Which specific aspects of drought conditions (such as the magnitude and duration of low flows, and the timing of low and high flows) most influence nitrate accumulation in an agricultural basin and its subsequent flushing to a stream?

- Based on these results, might it be possible to develop a better statistical model of nitrate export that simultaneously uses both current and antecedent flow conditions to estimate concentration?

- How would one go about using new, high-frequency nitrate sensor data to improve understanding on how antecedent flows influence solute concentration? Will these new, richer data sets facilitate understanding of storage, transport, and processing of nitrogen within watersheds at this scale?

The results of our analysis suggest that nitrate transport in the Mississippi River basin is not a simple product of current hydrologic conditions and nitrate concentrations, but rather an integration of current conditions with past inputs of water and changes in nitrate supply that vary regionally and with contemporaneous flow class. Therefore, an improved understanding of the evolving pattern of nitrate fluxes from the entire Mississippi River basin will require detailed analysis of the diverse patterns of nitrate export from the various subbasins and their interaction with similarly variable spatial and temporal patterns of climate and management practices. As a result, the evaluation of progress in nutrient management will benefit from consideration of antecedent influences.

Acknowledgements. We thank the many US Geological Survey (USGS) personnel who collected the extensive data used in this report. We thank Brent Aulenbach (USGS) for compiling and preparing the streamflow and water chemistry data used in this report, and James Falcone (USGS) for providing geographic information for the study basins. We also thank several reviewers who posed questions that challenged us to sharpen our thinking about the major points in this paper.

Edited by: M. Hrachowitz

\section{References}

Alexander, R. B., Smith, R. A., Schwarz, G. E., Boyer, E. W., Nolan, J. V., and Brakebill, J. W.: Differences in Phosphorous and Nitrogen Delivery to The Gulf of Mexico from the Mississippi River Basin, Environ. Sci. Technol. 42, 822-830, 2008.
Ashby, J. A., Bowden, W. B., and Murdoch, P. S.: Controls on denitrification in riparian soils in headwater catchments of a hardwood forest in the Catskill Mountains, USA, Soil Biol. Biochem., 30, 853-864, 1998.

Aulakh, M. S. and Bijay-Singh: Nitrogen losses and fertilizer N use efficiency in irrigated porous soils, Nutrient Cy. Agroecosyst., 27, 197-212, 1997.

Aulenbach, B. T., Buxton, H. T., Battaglin, W. A., and Coupe, R. H.: Flow and nutrient fluxes of the Mississippi-Atchafalaya River Basin and subbasins for the period of record through 2005, US Geological Survey Open-File Report 2007-1080, 2007.

Bernal, S. and Sabater, F.: Changes in discharge and solute dynamics between hillslope and valley-bottom intermittent streams, Hydrol. Earth Syst. Sci., 16, 1595-1605, doi:10.5194/hess-16-15952012, 2012.

Biron, P. M., Roy, A. G., Courschesne, F., Hendershot, W. H., Cote, B., and Fyles, J.: The effect of antecedent moisture conditions on the relationship of hydrology to hydrochemistry in a small forested watershed, Hydrol. Process. 13, 1541-1555, 1999.

Bowman, J. A. and Collins, M. A.: Impacts of irrigation and drought on Illinois ground-water resources, State of Illinois, Department of Energy and Natural Resources, Illinois state water survey, ISWS/RI-109/87, 31 pp., 1987.

Brown, J. B., Sprague, L. A., and Dupree, J. A.: Nutrient sources and transport in the Missouri River basin, with emphasis on the effects of irrigation and reservoirs, J. Am. Water Resour. Assoc. 47, 1034-1060, 2011.

Burkart, M. R. and Stoner, J. D.: Chapter 7. Nitrogen in groundwater associated with agricultural systems, in: Nitrogen in the Environment: Sources, Problems, and Management (2nd Edn.), Academic Press/Elsevier, Amsterdam, edited by: Hatfield, R. F. and Follett, J. L., 177-202, 2008.

Burt, T. and Worrall, F.: Non- stationary in long time series: some curious reversals in the "memory" effect, Hydrol. Process. 21, 3529-3531, 2007.

Burt, T. P. and Worrall, F.: Stream nitrate levels in a small catchment in south west England over a period of 35 years (1970-2005), Hydrol. Process. 23, 2056-2068, 2009.

Burt, T. P., Arkell, B. P., Trudgill, S. T., and Walling, D. E.: Stream nitrate levels in a small catchment in south west England over a period of 15 years, Hydrol. Process. 2, 267-284, 1988.

Cooper, R., Thoss, V., and Watson, H.: Factors influencing the release of dissolved organic carbon and dissolved forms of nitrogen from a small upland headwater during autumn runoff events, Hydrol. Process. 21, 622-633, 2007.

Creed, I. F. and Band, L. E.: Export of nitrogen from catchments within a temperate forest: Evidence for a unifying mechanism regulated by variable source area dynamics, Water Resour. Res., 34, 3105-3120, 1998.

de Klein, C. A. M. and van Logtestijn, R. S. P.: Denitrification in grassland soils in the Netherlands in relation to irrigation, $\mathrm{N}$ application rate, soil water content and soil temperature, Soil Biol. Biochem., 28, 231-237, 1996.

Detty, J. M. and McGuire, K. J.: Topographic controls on shallow groundwater dynamics: implications of hydrologic connectivity between hillslopes and riparian zones in a till mantled catchment, Hydrol. Process., 24, 2222-2236, 2010. 
Dinnes, D. L., Karlen, D. L., Jaynes, D. B., Kaspar, T. C., Hatfield, J. L., Colvin, T. S., and Cambardella, C. A.: Nitrogen management strategies to reduce nitrate leaching in tile-drained Midwestern soils, Agron. J., 94, 153-171, 2002.

Donner, S. D. and Scavia, D.: How climate controls the flux of nitrogen by the Mississippi River and the development of hypoxia in the Gulf of Mexico, Limnol. Oceanogr., 52, 856-861, 2007.

Emmerich, W. E. and Heitschmidt, R. K.: Drought and Grazing: II. Effects on runoff and water quality, J. Range Manage., 55, 229234, 2002.

Foster, I. D. L. and Walling, D. E.: The effects of the 1976 drought and autumn rainfall on stream solute levels, Earth Surf. Process. 3, 393-406, 1978.

Ferguson, R., Shapiro, C., Wortmann, C., Shaver, T., and Hergert, G.: University of Nebraska-Lincoln Extension, CropWatch, Nebraska crop production \& pest management information, Checking for Residual nitrate this spring: http://cropwatch.unl.edu/ web/cropwatch/archive?articleID=5121463 (last access: 21 June 2013), 2013.

Garrett, J.: Concentrations, loads and yields of select constituents from major tributaries of the Mississippi and Missouri Rivers in Iowa, Water Years 2004-2008, US Geological Survey Scientific Investigations Report 2012-5240, 72 pp., 2012.

Gascuel-Odoux, C., Aurousseau, P., Durand, P., Ruiz, L., and Molenat, J.: The role of climate on inter-annual variation in stream nitrate fluxes and concentrations, Sci. Total Environ. 408, 56575666, 2010

Groves, S. J. and Bailey, R. J.: The influence of sub-optimal irrigation and drought on crop yield, $\mathrm{N}$ uptake and risk of $\mathrm{N}$ leaching from sugarbeet, Soil Use Manage., 13, 190-195, 1997.

Helsel, D. R. and Hirsch, R. M.: Statistical methods in water resources, Techniques of water-resources investigations, Book 4, chapter A3, US Geological Survey, 522 pp., 2002.

Hirsch, R. M., Moyer, D. L., and Archfield, S. A.: Weighted regressions on time, discharge, and season (WRTDS), with an application to Chesapeake Bay river inputs, J. Am. Water Resour. Assoc. 46, 857-880, 2010.

Hornberger, G. M., Bencala, K. E., and McKnight, D. M.: Hydrological controls on dissolved organic carbon during snowmelt in the Snake River near Montezuma, Colorado, Biogeochemistry 25, 147-165, 1994.

Hrachowitz, M., Savenije, H. H. G., Blöschl, G., McDonnell, J. J., Sivapalan, M., Pomeroy, J. W., Arheimer, B., Blume, T., Clark, M. P., Ehret, U., Fenicia, F., Freer J. E., Gelfan, A., Gupta, H. V., Hughes, D. A., Hut, R. W., Montanari, A., Pande, S., Tetzlaff, D., Troch, P.A., Uhlenbrook, S., Wagener, T., Winsemius, H. C., Woods, R. A., Zehe, E., and Cudennec, C.: A decade of Predictions in Ungauged Basins (PUB) - a review, Hydrol. Sci. J., 58, 1198-1255, 2013.

Kalkhoff, S. J.: Occurrence and Transport of Nutrients in the Missouri River Basin, April through September 2011, U.S. Geological Survey Professional Paper 1798-G, 23 pp., 2013.

Lange, J. and Haensler, A.: Runoff generation following a prolonged dry period, J. Hydrol., 464-465, 157-164, 2012.

Lucey, K. J. and Goolsby, D. A.: Effects of Climatic Variations over 11 Years on Nitrate-Nitrogen Concentrations in the Raccoon River, Iowa, J. Environ. Qual., 22, 38-46, 1993.
Macrae, M. L., English, M. C., Schiff, S. L., and Stone, M.: Influence of antecedent hydrologic conditions on patterns of hydrochemical export from a first-order agricultural watershed in Southern Ontario, Canada, J. Hydrol., 389, 101-110, 2010.

National Oceanic and Atmospheric Administration, National Climatic Data Center, Climate Monitoring Group Palmer Hydrological Drought Index - May 2012 to April 2013, available at: http://www.ncdc.noaa.gov/oa/climate/research/prelim/ drought/palmer.html (last access: 21 June 2013), 2013.

Nolan, J. V., Brakebill, J. W., Alexander, R. B., and Schwarz, G. E., ERF1_2 - Enhanced River Reach File 2.0: http://water. usgs.gov/GIS/metadata/usgswrd/XML/erf1_2.xml (last access: 2 June, 2013), 2002.

Pervez, M. S. and Brown, J. F.: Mapping irrigated lands at 250-m scale by merging MODIS data and national agricultural statistic, Remote Sens., 2, 2388-2414, 2010.

Rabalais, N. N. and Turner, R. E.: Hypoxia in the northern Gulf of Mexico: description, causes and change, in: Coastal Hypoxia: Consequences for living resources and ecosystems, Coastal and Estuarine Studies, American Geophysical Union, 1-36, 2001.

Randall, G. W., Vetsch, J. A., and Huffman, J. R.: Nitrate losses in subsurface drainage from a corn-soybean rotation as affected by time of nitrogen application and use of Nitrapyrin, J. Environ. Qual., 32, 1764-1772, 2003.

Rehm, G., Schmitt, M., and Eliason, R., University of MinnesotaExtension, Using soil nitrate test in Minnesota, WW-07310: available at: http://www.extension.umn.edu/distribution/ cropsystems/DC7310.html (last access: 21 June 2013), 2009.

Rozemeijer, J. C., van der Velde, Y., van Geer, F. C., Bierkens, M. F. P., and Broers, H. P.: Direct measurements of the tile drain and groundwater flow route contributions to surface water contamination: From field-scale concentration patterns in groundwater to catchment-scale surface water quality, Environ. Pollut., 158, 3571-3579, 2010.

Sanford, W. E. and Pope, J. P.: Quantifying Groundwater's Role in Delaying Improvements to Chesapeake Bay Water Quality, Environ. Sci. Technol., 47, 13330-13338, 2013.

Sawyer, J.: Iowa State University-Extension, Soil profile nitrate in corn fields following the 2012 drought, available at: http://www. extension.iastate.edu/CropNews/2013/0221 sawyer.htm (last access: 21 June 2013), 2013.

Scavia, D., Rabalais, N. N., Turner, R. E., Justic, D., and Wiseman, W. J.: Predicting the response of Gulf of Mexico hypoxia to variation in Mississippi River nitrogen load, Limnol. Oceanogr., 48, 951-956, 2003.

Shaman, J., Steiglitz, M., and Burns, D.: Are big basins just the sum of small catchments?, Hydrol. Process., 18, 3195-3206, 2004.

Sidle, R. C.: Field observations and process understanding in hydrology: essential components in scaling, Hydrol. Process., 20, 1439-1445, 2006.

Sivapalan, M.: Process complexity at hillslope scale, process simplicity at the watershed scale: is there a connection?, Hydrol. Process., 17, 1037-1041, 2003.

Soulsby, C., Petry, J., Brewer, M. J., Dunn, S. M., Ott, B., and Malcolm, I. A.: Identifying and assessing uncertainty in hydrological pathways: a novel approach to end member mixing in a Scottish agricultural catchment, J. Hydrol., 274, 109-128, 2003. 
Soulsby, C., Tetzlaff, D., Dunn, S. M., and Waldron, S.: Scaling up and out in runoff process understanding: insights from nested experimental catchment studies, Hydrol. Process., 20, 2461-2465, 2006.

Sprague, L. A., Hirsch, R. M., and Aulenbach, B. T.: Nitrate in the Mississippi River and its tributaries, 1980 to 2008: Are we making progress?, Environ. Sci. Technol., 45, 7209-7216, 2011.

Stites, W. and Kraft, G. J.: Nitrate and chloride loading to groundwater from an irrigated north-central US sand-plain vegetable field, J. Environ. Qual., 30, 1176-1184, 2001.

Turner, R. E., Rabalais, N. N., and Justic, D.: Predicting summer hypoxia in the northern Gulf of Mexico: Riverine N, P, and Si loading, Mar. Pollut. Bull., 52, 139-148, 2006.

Vecchia, A.: Relation between climate variability and stream water quality in the continental United States, Hydrol. Sci. Technol., 19, 77-98, 2003.
Vecchia, A. V., Martin, J. D., and Gilliom, R. J.: Modeling variability and trends in pesticide concentrations in streams, J. Am. Water Resour. Assoc., 44, 1308-1324, 2008.

Walling, D. E. and Foster, I. D. L.: Variations in the natural chemical concentration of river water during flood flows, and the lag effect: some further comments, J. Hydrol., 26, 237-244, 1975.

Webb, B. W. and Walling, D. E.: Stream solute behavior in the River Exe basin, Devon, UK, Dissolved loads of rivers and surface water quantity/quality relationships, Proceedings of the Hamburg Symposium, August 1983, IAHS Publ no. 141, 153-169, 1984.

Welsch, D. L., Kroll, C. N., McDonnell, J. J., and Burns, D. A.: Topographic controls on the chemistry of subsurface stormflow, Hydrol. Process., 15, 1925-1938, 2001. 